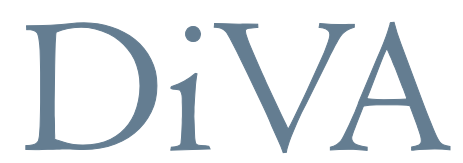

http://uu.diva-portal.org

This is an author produced version of a paper published in European Economic Review. This paper has been peer-reviewed but does not include the final publisher proof-corrections or journal pagination.

Citation for the published paper:

Andreea Mitrut, Katarina Nordblom

"Social Norms and Gift Behavior: Theory and Evidence from Romania" European Economic Review, 2010, Vol. 54, Issue 8, pp. 998-1015

URL: http://dx.doi.org/ 10.1016/j.euroecorev.2010.03.002

Access to the published version may require subscription.

Published with permission from: Elsevier 


\title{
Social Norms and Gift Behavior: Theory and Evidence from Romania *
}

\author{
Andreea Mitrut and Katarina Nordblom ${ }^{\dagger}$
}

May 21, 2010

\begin{abstract}
In many developing and transitional countries with limited public income redistribution, inter-household transfers in general, and gifts in particular, are sizable and very important. We use unique Romanian survey data that enables us to isolate pure gifts from other private transfers. We explicitly focus on the importance of community-wide social norms, and find that they indeed play a major role for both the occurrence and the values of gifts received. More exactly, our results suggest that the overall predominant gift motive among Romanian households is a norm of reciprocity. Moreover, this norm seems to be dominating for gifts to middle- and high-income households. Even though poor households receive to the same extent, norms of both impure altruism and reciprocity tend to be important. Hence, although the poor may not reciprocate gifts to the same extent as the rich, they still receive, since there is a social norm to give, especially to the poor.

Keywords: gifts, transfers, altruism, reciprocity, Romania, social norms.

JEL classification: Z13, R20, I30, D10.

*We appreciate very useful comments and suggestions from two anonymous referees, Rolf Aaberge, Daniela Andrén, Fredrik Carlsson, Martin Dufwenberg, Marcel Fafchamps, Lennart Flood, Olof Johansson-Stenman, Henry Ohlsson, Ola Olsson, Amrish Patel, Violeta Piculescu, Bo Sandelin, Johan Stennek, Erik Ø. Sørensen, Elias Tsakas, FrançoisCharles Wolff, and seminar participants at ESPE, SMYE, FISS conferences, the University of Gothenburg, Uppsala University, and Umeå University.

${ }^{\dagger}$ Department of Economics, Uppsala Univerity, Box 513, SE-751 20 Uppsala, Sweden and the University of Gothenburg, Sweden. E-mail: andreea.mitrut@nek.uu.se or katarina.nordblom@economics.gu.se. Mitrut acknowledges financial support from the Jan Wallander and Tom Hedelius Foundation. Nordblom thanks the Malmsten Foundation for
\end{abstract} financial support. 


\section{Introduction}

Private gift transfers are important all over the world. People give gifts to family, friends, neighbors, etc. Parents may give to their children out of love and affection, or one may help a person in a bad situation out of compassion or empathy. However, this is not the whole picture. In everyday life there are many situations where gift giving is rather a result of fulfilling some social norms and customs. Imagine a wedding; no one shows up empty-handed, since it is usually a social norm to bring a gift. Also imagine a neighborhood where neighbors help each other with different tasks. Then there is a social norm to contribute, and no one wants to appear less generous than others. In such a reciprocal network, a person is more inclined to give to those who have been generous. This kind of behavior is likely to be especially important in transition and developing countries where people adopt and recognize the value of certain norm-guided behaviors (Platteau, 2006). ${ }^{1}$ Yet, most of the existing work on private transfers in developing countries has been focused on altruistic and exchange motives, and not on such norms (see, e.g., Cox et al., 1998, 2004; Cai et al., 2006; Kazianga, 2006).

The overall purpose of the present paper is to shed some light on why people give gifts to each other. Most previous studies have been concerned with private transfers in general, but since we can easily imagine that people may have different motives for lending money and for giving pure gifts, we believe that a lot can be gained in terms of understanding these behaviors by studying one kind of transfer at a time. We use an unusually rich Romanian data set that distinguishes among pure gifts, loans, exchanges of services, and payments. This enables us to isolate pure gifts from other transfers in a way that was not possible in most previous studies. We concentrate on gifts, since they are the most frequent and the most sizable kind of private transfer in Romania (Amelina et al., 2004). Hence, we exclude transfers explicitly made

\footnotetext{
${ }^{1}$ Social norms are usually recognized as an essential component of social capital (see Keefer and Knack, 2008, for a review on the link between social capital and social norms). Also Portes (1998) considers the norms of reciprocity and some other internalized norms (such as donating to charity, obeying traffic rules) when examining the "microfoundations" of social capital.
} 
as loans or for exchange reasons. ${ }^{2}$ Our main finding is that social norms have a strong impact on gift transfers in Romania and, as far as we know, this is the first economic study that explicitly takes social norms into account when studying inter-household gifts. However, an increasing number of papers consider the social dimension of private transfers (see, e.g., Sugden, 1984; Ravallion and Dearden, 1988; Seinen and Schram, 2006; Cassar et al., 2007; Platteau and Sekeris, 2007).

Romania is a country with limited public transfers and where interhousehold transfers in general, and gifts in particular, are very important (Amelina et al., 2004). Ninety-five percent of our sampled households were involved in gift transfers during 2002. Sociological and anthropological studies have documented the social importance of gift transfers in Romania, especially in terms of gifts connected to important traditions and ceremonies such as the alms and funerals (Kligman, 1988; Hann, 2006). ${ }^{3}$ In developing and transition countries, inter-household transfers are typically larger and much more common than in Western countries. In Burkina Faso, private transfers received constitute 33 percent of recipient household income on average (Kazianga, 2006). As a comparison, they account for 4.6 percent in Poland (Cox et al., 1997) and for around 12 percent in Romania, while in the U.S. the proportion is only about 1 percent (Schoeni, 1997). Still, there are very few studies on inter-household transfers in transition and developing countries, and many of them have focused on risk-sharing mechanisms and the role of gifts and other informal transfers as buffers against different types of shocks (see, e.g., Fafchamps, 1992; Fafchamps and Lund, 2003).

We set up a simple theoretical model in which social norms related to $\mathrm{im}$ pure altruism and reciprocity motivate gift behavior. In particular, impure altruism refers to that, in some situations or to certain people (like the poor), one may feel socially obliged to give, irrespective of the recipient's own gift

\footnotetext{
${ }^{2}$ We also exclude the "negative" side of gifts, i.e., bribing, although, e.g., Schechter (2007) shows that in rural Paraguay, gifts can be given to potential thieves to deter theft.

${ }^{3}$ Moreover, among many other religious rituals, alms are offered at many other occasions, e.g., 40 days after the funeral and during Mosi - an important Orthodox ritual (i.e., Christmas Mosi, Eastern Mosi, etc.) where besides free food and drinks, the family of the deceased gives clothes, animals and other objects (such as furniture) (Vaduva, 1997; Pop, 1999).
} 
behavior, and it may be induced by, e.g., traditions (cf. the alms gift). We also take reciprocity into account, and assume that people want to reward those who have shown generous behavior(cf. the above-mentioned neighborhood). Our two gift motives result in different predictions regarding both the occurrence and the magnitude of gifts: the impure altruism norm predicts that gifts are weakly negatively correlated with recipient income, while reciprocity predicts a positive relationship since higher income increases the possibility to take part in informal reciprocal networks. Moreover, we expect larger gifts in communities where social norms are stronger. All these predictions are then tested empirically.

A strong and novel result is that social norms have a positive impact on both the occurrence of gifts and the gift value conditional on there being a positive gift. Our findings suggest that both the reciprocity and the impure altruism norm may be simultaneously present, but that the reciprocity norm is the overall dominating gift motive among Romanian households. However, we uncover different dominating motives for gifts to the poor and to the non-poor even though the two groups receive to the same extent. We find that the reciprocity norm is dominating for gifts to high- and middle-income households, while we can not disentangle one dominating gift motive for the poor, since both norms of reciprocity and of impure altruism seem to matter. Moreover, the lower the income, the stronger the relative importance of impure altruism as compared to the reciprocity norm.

The remainder of the paper is organized as follows. In Section 2, we discuss our two gift motives and set up a simple formal model of private gift giving. Then we derive comparative statics to be tested in the empirical part. Section 3 presents the data, and our general estimation results for receiving are presented and analyzed in Section 4. In Section 5, we analyze motives for gift giving to rich and poor separately. We also look into potential differences between money and in-kind transfers in Section 6. Finally, Section 7 concludes the paper. 


\section{Private gift giving}

As mentioned in the introduction, there are different theoretical explanations for gift behavior, and as discussed by Schokkaert (2006), multiple motives are likely to be present at the same time. In what follows we set up a simple model that highlights a few important aspects of gift giving that we use as a framework to interpret our empirical results. More exactly, our model focuses on social norms as a key motive to inter-household gifts. Norms could be especially decisive for gifts in societies where most gifts are transferred between non-family members. One example is Romania, where norms of gift giving are affected by, e.g., traditional and religious rituals (Kligman, 1988; Vaduva, 1997; Pop, 1999) and do therefore vary across communities. In what follows, we assume that individuals take these social norms as given in their decision making. ${ }^{4}$ We explicitly consider two distinct norm-related gift motives in our model: impure altruism and reciprocity, two motives that according to, e.g., Sacco et al. (2006), often go together. We briefly discuss the motives in Section 2.1 before presenting the formal model in Section 2.2.

\section{$2.1 \quad$ Gift motives}

\subsubsection{Impure altruism}

The impure altruism gift motive consists of two components: one that is directly concerned with others' well-being (like pure altruism) and one that gives the donor pleasure from the act of giving. Let us briefly discuss each of these two components: According to the first, we assume that there is a norm that one should give to those in need, a norm that will induce the same gift behavior as pure altruism. Sociological and ethnological studies in Romania suggest that gifts toward the poor are more common in communities with

\footnotetext{
${ }^{4}$ It is likely that a specific individual at a specific instant considers it as exogenous although norms may be endogenous in the long run. E.g., Fischer and Huddart (2008) model how social norms evolve as a function of others' behavior and Lindbeck et al. (1999) claim that the more people who adhere to the social norm, the stronger the social pressure. In Brekke et al. (2003), the social or moral ideal is determined endogenously, but taken as given in the individual's decision making.
} 
strong social norms related to gift giving (Kligman, 1988; Pop, 1999) and that these kinds of norms are indeed effective.

The second component is closely linked to Andreoni's warm-glow notion. However, Schokkaert (2006) argues that an intrinsic feeling of duty may be more appropriate when we think of inter-household gifts although the resulting gift behavior is likely to be similar. If sufficiently many people hold such intrinsic duties, they are likely to transform into social norms (see, e.g., Schokkaert, 2006; Portes, 1998; Fehr and Falk, 2002). Hence, we assume that people in some situations feel a duty to give, and that the strength of the social norm determines the strength of this feeling. In some situations, people are simply expected to give, and the more they give, the better it is. The gifts given for religious ceremonies, such as requiems and alms, are an illustrative Romanian example. E.g., when a person dies, the relatives invite the whole neighborhood, both rich and poor, to a requiem and give, e.g., food, drink, and clothes to the guests for free (Anghelescu, 1999). ${ }^{5}$

Taken together, according to impure altruism, gifts should be given irrespective of the recipient's gift behavior; no return gift is required or even expected. The two components of impure altruism mostly predict the same qualitative results in the theoretical model and in our empirical part we will not be able to distinguish between the two, so there we regard impure altruism as a single motive.

\subsubsection{Reciprocity}

Even if receiving a gift is by definition free, once you have received a gift you may want to reciprocate it with another gift. Sugden (1984), Rabin (1993), Fehr and Gächter (2000), and Dufwenberg and Kirchsteiger (2004) among others have found that perceived fairness is very important and that people therefore tend to act in a reciprocal way. If gifts create a moral indebtedness, people want to reciprocate to restore balance between gifts given and gifts

\footnotetext{
${ }^{5}$ To avoid misfortune, "the living are obliged to offer alms for the dead, primarily in the form of commemorative meals and prayer, in addition to those acts that are ritually performed during the burial rites.(...) While the meal is in progress any passerby is invited" (Kligman, 1988). In many parts of Romania, people also receive new clothes, money, or new furniture as gifts during this event.
} 
received. In a social context, there is likely a social norm of reciprocating gifts (see, e.g., Sacco et al., 2006; Fehr and Falk, 2002). Then the value of a counter-gift should typically be in parity with the value of the original gift. ${ }^{6}$ There could also be a more general kind of reciprocity where a generous behavior is rewarded by a third party, just like the "reverse reciprocity" discussed by Kolm (2006) and the "indirect reciprocity" found by Seinen and Schram (2006). According to such indirect reciprocity, one gives to people who have given to others, e.g., in the neighborhood. Unfortunately, our data does not allow us to distinguish between the two kinds of reciprocity, so in the empirical part we only regard reciprocity as such, and in the theoretical model we, for expositional convenience, only consider direct reciprocity between two individuals. $^{7}$

\subsection{The model}

Let us now connect our gift motives in a simple formal framework. Consider two individuals, 1 and 2 (possibly two neighbors), who interact with each other and have identical utility functions (The exposition below is made for individual 1 , but it is corresponding for 2 ):

$$
U_{1}=u\left(c_{1}\right)+\eta\left[\delta\left(x_{1}, c_{2}\right)+\rho\left(x_{1}, x_{2}\right)\right]
$$

where $u\left(c_{1}\right)$ is the utility of own consumption for 1 , with $u^{\prime}>0, u^{\prime}(0)=$ $\infty$ and $u^{\prime \prime}<0$. Own consumption, $c_{1}=y_{1}+x_{2}-x_{1}$, where $y_{1}$ is pretransfer income and $x_{1} \in\left[0, y_{1}\right]$ is a gift from 1 to 2 , and $x_{2} \in\left[0, y_{2}\right]$ is a gift in the opposite direction. ${ }^{8}$ The two individuals also want to comply with social norms of gift giving, consisting of impure altruism (represented by $\left.\delta\left(x_{1}, c_{2}\right)\right)$ and of reciprocity (represented by $\left.\rho\left(x_{1}, x_{2}\right)\right)$. In the community where they live, there is a certain, to them exogenous, norm strength, $\eta>$

\footnotetext{
6"Give as much as you receive and all is for the best" (Mauss, 1954).

${ }^{7}$ It is plausible that people perceive direct reciprocity to be more important than indirect. Expanding the model to also incorporate indirect reciprocity gives at hand that both kinds of reciprocity give the same qualitative predictions.

${ }^{8}$ Gifts received from donors other than 2 may be included in $y_{1}$, but those gifts are treated as exogenous constants.
} 
0, which measures the overall strength of the two separate norms. Hence, in a community with a high $\eta$, to comply with both impure altruism and reciprocity is more important than in a community where $\eta$ is low. ${ }^{9}$

The impure altruism motive, $\delta\left(x_{1}, c_{2}\right)$, includes one duty-related component and one concerned with the other's utility and is additively separable

$$
\delta\left(x_{1}, c_{2}\right)=v\left(x_{1}\right)+\alpha u\left(c_{2}\right) .
$$

The duty component is captured by the function $v$ : the social value increases in the gift given, and just like Andreoni's (1989, 1990) warm glow, $v^{\prime}>0$ and $v^{\prime \prime}<0$. In the second argument, the other's utility of consumption, $u\left(c_{2}\right)$, is weighted by the parameter $\alpha>0$. We make the plausible assumption that $\eta \alpha<1$, which implies that one values one's own utility of consumption higher than that of the other.

The reciprocity norm is captured by the symmetric and concave function $\rho\left(x_{1}, x_{2}\right)$ (the same for both individuals). This norm states that the gifts that the two give to each-other should preferably be of equal size, so $\rho_{1}^{\prime}>0$ if $x_{1}<x_{2}$ and $\rho_{1}^{\prime}<0$ whenever $x_{1} \geq x_{2}$ (and likewise for $\rho_{2}^{\prime}$ ). ${ }^{10}$ If $x_{2}>x_{1}$, the inequality diminishes if $x_{1}$ increases, which is socially desirable, while it increases if $x_{1}>x_{2}$. Hence, at most one of the partial derivatives can be positive. Moreover, $\rho_{11}^{\prime \prime}<0, \rho_{22}^{\prime \prime}<0$ and $\rho_{12}^{\prime \prime}>0$. Hence, the marginal social value of $x_{1}$ increases in $x_{2}$, so that a larger gift from 2 tends to induce a larger return gift. To assure the reasonable result that $\frac{d x_{1}}{d x_{2}}<1$ (and $\frac{d x_{2}}{d x_{1}}<1$ ), we make the sufficient assumption that

Assumption 1. $\rho_{12}^{\prime \prime}+\rho_{11}^{\prime \prime}<0, \quad \rho_{12}^{\prime \prime}+\rho_{22}^{\prime \prime}<0 .{ }^{11}$

We model the gift decisions as a simultaneous game where the two individuals decide on a gift taking the other's gift as given. ${ }^{12}$ Hence, we formulate the maximization problem for 1 (and likewise for 2):

\footnotetext{
${ }^{9}$ In the theoretical model, $\eta$ may seem superfluous, but when we turn to the empirical analysis, social-norm strength is a key element, since it varies across communities studied. For pedagogical reasons, we therefore include it already in the theoretical model.

${ }^{10}$ Henceforth, we refer to $\rho_{1}^{\prime}$ as the derivative of $\rho$ w.r.t. $x_{1}$ and $\rho_{2}^{\prime}$ as the derivative w.r.t. $x_{2}$.

${ }^{11} \mathrm{~A}$ proof that this assumption is sufficient for $\frac{d x_{1}}{d x_{2}}<1$ is found in Appendix A.

${ }^{12}$ It would perhaps be more natural to think of reciprocal gifts as a repeated sequential
} 


$$
\max _{x_{1}} U_{1}=u\left(c_{1}\right)+\eta\left[\delta\left(x_{1}, c_{2}\right)+\rho\left(x_{1}, x_{2}\right)\right]
$$

$$
\begin{aligned}
\text { subject to } & c_{1}=y_{1}-x_{1}+x_{2}, \\
\text { and } & x_{1} \geq 0
\end{aligned}
$$

When 1 solves his maximization problem (3) given 2's gift $x_{2}$, the firstorder conditions are:

$$
\begin{aligned}
& \frac{\partial U_{1}}{\partial x_{1}}=-u_{1}^{\prime}+\eta\left[v_{x_{1}}^{\prime}+\alpha u_{2}^{\prime}+\rho_{1}^{\prime}\right] \leq 0, \\
& x_{1} \geq 0, \quad \frac{\partial U_{1}}{\partial x_{1}} x_{1}=0
\end{aligned}
$$

where the subscript denotes the donor and $v_{x_{1}}^{\prime}$ refers to $v^{\prime}$ at $x_{1}$.

Likewise, the first-order conditions for 2 are:

$$
\begin{aligned}
& \frac{\partial U_{2}}{\partial x_{2}}=-u_{2}^{\prime}+\eta\left[v_{x_{2}}^{\prime}+\alpha u_{1}^{\prime}+\rho_{2}^{\prime}\right] \leq 0, \\
& x_{2} \geq 0, \quad \frac{\partial U_{2}}{\partial x_{2}} x_{2}=0
\end{aligned}
$$

If the inequality in (4) is always strict, even when $x_{1}=0$, then 1 will give no gift. In an interior solution, $x_{1}>0$ is chosen such that 1 's marginal utility of consumption equals the marginal social value of giving, given the behavior of 2.The two individuals' best-response functions are implicitly given by (4) and (5), and together they determine the Nash equilibrium of gift giving $\left(x_{1}^{*}, x_{2}^{*}\right)$. There are four potential equilibria to consider (see Table 1): neither of them gives (A), both give (D), or just one of them gives (B and C). However, for each couple of individuals (1 and 2), there is one unique Nash equilibrium determining gift behavior depending on their incomes and

game rather than as a simultaneous one. However, the Nash equilibria in the simultaneous game are identical to those in an infinitely repeated sequential game (see, e.g., Osborne and Rubinstein, 1994). 
strength of social norms. ${ }^{13}$

Table 1: Conditions for possible equilibria

\begin{tabular}{|c|c|c|}
\hline & $x_{1}^{*}=0$ & $x_{1}^{*}>0$ \\
\hline$x_{2}^{*}=0$ & $\begin{array}{c}\mathrm{A} \\
u_{1}^{\prime}>\eta\left(v_{0}^{\prime}+\alpha u_{2}^{\prime}\right) \\
u_{2}^{\prime}>\eta\left(v_{0}^{\prime}+\alpha u_{1}^{\prime}\right)\end{array}$ & $\begin{array}{c}\mathrm{B} \\
u_{1}^{\prime}=\eta\left(v_{x_{1}}^{\prime}+\alpha u_{2}^{\prime}+\rho_{1}^{\prime}\right) \\
u_{2}^{\prime}>\eta\left(v_{0}^{\prime}+\alpha u_{1}^{\prime}+\rho_{2}^{\prime}\right)\end{array}$ \\
\hline$x_{2}^{*}>0$ & $\begin{array}{c}\mathrm{C} \\
u_{1}^{\prime}>\eta\left(v_{0}^{\prime}+\alpha u_{2}^{\prime}+\rho_{1}^{\prime}\right) \\
u_{2}^{\prime}=\eta\left(v_{x_{2}}^{\prime}+\alpha u_{1}^{\prime}+\rho_{2}^{\prime}\right)\end{array}$ & $\begin{array}{c}\mathrm{D} \\
u_{1}^{\prime}=\eta\left(v_{x_{1}}^{\prime}+\alpha u_{2}^{\prime}+\rho_{1}^{\prime}\right) \\
u_{2}^{\prime}=\eta\left(v_{x_{2}}^{\prime}+\alpha u_{1}^{\prime}+\rho_{2}^{\prime}\right)\end{array}$ \\
\hline
\end{tabular}

Reflecting over the four possible equilibria, we see that equilibrium (A) is likely to occur if both 1 and 2 are poor (and have high marginal utility of consumption) or live in a community where the social norms of gift giving are weak. An equilibrium where only one gives (B or C) can only occur due to impure altruism and only if the donor has a higher income than the recipient. ${ }^{14}$ In equilibrium $\mathrm{D}\left(x_{1}^{*}>0, x_{2}^{*}>0\right)$, reciprocity may also be an effective gift motive. This equilibrium occurs if the social norms are strong and/or the two have sufficiently low marginal utilities of consumption. Since the main purpose of this model is to generate predictions for our empirical part, we now examine what makes us end up in an equilibrium where $x_{1}^{*}>0$ rather than in an equilibrium where $x_{1}^{*}=0$ (which gives predictions for the probits in our empirical part) and, then, what affects the gift value conditional on there being a positive gift, i.e., when $x_{1}^{*}>0$. (Note that the choice of $x_{1}^{*}$ as the object of study rather than $x_{2}^{*}$ is completely arbitrary.) When looking at the decision of individual 1, we have to consider two different cases, depending on the actions of 2 . More exactly, we study what would be needed

\footnotetext{
${ }^{13}$ The conditions in Table 1 are mutually exclusive, so each couple ends up in one and only one square. That $\left(x_{1}^{*}=0, x_{2}^{*}=0\right)$ is unique in $\mathrm{A}$ is trivial. In (11)-(13), the secondorder conditions prove that the equilibria are unique in $\mathrm{B}\left(x_{1}^{*}>0, x_{2}^{*}=0\right)$ and $\mathrm{C}$, and in Appendix $\mathrm{A}$ it is proven that there is a unique equilibrium $\left(x_{1}^{*}>0, x_{2}^{*}>0\right)$ in $\mathrm{D}$.

${ }^{14}$ For proof, see Appendix A.
} 
to go from $x_{1}^{*}=0$ to $x_{1}^{*}>0$ in equilibrium $\mathrm{A}$ (when $x_{2}^{*}=0$ ) and in $\mathrm{C}$ (when $\left.x_{2}^{*}>0\right)$, respectively.

\subsubsection{Comparative statics concerning $x_{1}^{*}$ when $x_{2}^{*}=0$}

Let us start with the situation where $x_{2}^{*}=0$. Here there is no effective reciprocity going on, so we only have to consider impure altruism. If we are in equilibrium A, no one gives and 1's first-order condition (4) can be written as:

$$
\left.\Delta \equiv \frac{\partial U_{1}}{\partial x_{1}}\right|_{x_{2}^{*}=0}=-u_{1}^{\prime}+\eta\left(v_{0}^{\prime}+\alpha u_{2}^{\prime}\right)<0 .
$$

$\Delta$ can be viewed as a latent variable determining the gift decision, so that $x_{1}^{*}=0$ as long as $\Delta<0$. Differentiating $\Delta$, we therefore derive comparative statics for 1 's gift decision when $x_{2}^{*}=0$ :

$$
\begin{aligned}
& \frac{\partial \Delta}{\partial y_{1}}=-u_{1}^{\prime \prime}>0, \\
& \frac{\partial \Delta}{\partial y_{2}}=\eta \alpha u_{2}^{\prime \prime}<0, \\
& \frac{\partial \Delta}{\partial \eta}=v_{0}^{\prime}+\alpha u_{2}^{\prime}>0 .
\end{aligned}
$$

The effect of $y_{1}$ is positive, implying that a richer person will be more likely to give than a poorer. On the other hand, if $y_{2}$ increases, then the impure altruism norm stating that one should give to the poor becomes less effective, thus 1 becomes even less likely to give, although giving out of duty is unaffected by $y_{2}$. Finally, if the social norm of gift giving increases, then a gift becomes more beneficial and therefore the effect on the gift decision is positive. Table 2 in Section 2.3 presents a summary of the comparative statics that we make use of in the empirical part.

We now turn to analyzing what affects the value of $x_{1}^{*}$ conditional on it actually being positive when 1 is the sole donor (i.e., in equilibrium B). In $\mathrm{B}$, the first-order condition (4) can be rewritten as 


$$
u_{1}^{\prime}=\eta\left(v_{x_{1}}^{\prime}+\alpha u_{2}^{\prime}+\rho_{1}^{\prime}\right)
$$

Since 1 is the sole donor, impure altruism is the only effective motive and $\rho_{1}^{\prime}<0$ since 1 obviously gives more than 2 . Differentiating (10) gives

$$
\begin{aligned}
& \frac{\partial x_{1}^{*}}{\partial y_{1}}=\frac{u_{1}^{\prime \prime}}{\Omega}>0, \\
& \frac{\partial x_{1}^{*}}{\partial y_{2}}=\frac{-\eta \alpha u_{2}^{\prime \prime}}{\Omega}<0, \\
& \frac{\partial x_{1}^{*}}{\partial \eta}=\frac{-\left(v_{x_{1}}^{\prime}+\alpha u_{2}^{\prime}+\rho_{1}^{\prime}\right)}{\Omega}=\frac{-u_{1}^{\prime}}{\Omega}>0,
\end{aligned}
$$

where $\Omega=u_{1}^{\prime \prime}+\eta\left(v_{x_{1}}^{\prime \prime}+\alpha u_{2}^{\prime \prime}+\rho_{11}^{\prime \prime}\right)<0$, assuring that there is a unique $x_{1}^{*}>0$ when $x_{2}^{*}=0$.

When 1 is the sole donor, the gift value increases in donor income and decreases in recipient income from the impurely altruistic motive that one should give particularly to poor people. Finally, a stronger social norm implies larger gifts.

\subsubsection{Comparative statics concerning $x_{1}^{*}$ when $x_{2}^{*}>0$}

Let us now turn to the situation where 2 already gives a gift to 1 (in C) and consider what affects 1 's decision to give to 2 . In this case, the gift can also be motivated by reciprocity. In $\mathrm{C}$, (4) can be written as

$$
\left.\Gamma \equiv \frac{\partial U_{1}}{\partial x_{1}}\right|_{x_{2}^{*}>0}=-u_{1}^{\prime}+\eta\left(v_{0}^{\prime}+\alpha u_{2}^{\prime}+\rho_{1}^{\prime}\right)<0,
$$

where $\rho_{1}^{\prime}>0$. When we differentiate (14) to derive comparative statics for the gift decision when $x_{2}^{*}>0$, we also need to consider the response from 2 when the exogenous variables change: 


$$
\begin{aligned}
& \frac{\partial \Gamma}{\partial y_{1}}=-u_{1}^{\prime \prime}\left(1+\frac{\partial x_{2}}{\partial y_{1}}\right)+\eta\left(-\alpha u_{2}^{\prime \prime}+\rho_{12}^{\prime \prime}\right) \frac{\partial x_{2}}{\partial y_{1}}>0, \\
& \frac{\partial \Gamma}{\partial y_{2}}=-u_{1}^{\prime \prime} \frac{\partial x_{2}}{\partial y_{2}}+\eta\left(\alpha u_{2}^{\prime \prime}\left(1-\frac{\partial x_{2}}{\partial y_{2}}\right)+\rho_{12}^{\prime \prime} \frac{\partial x_{2}}{\partial y_{2}}\right) \gtreqless 0, \\
& \frac{\partial \Gamma}{\partial \eta}=-u_{1}^{\prime \prime} \frac{\partial x_{2}}{\partial \eta}+v_{0}^{\prime}+\alpha u_{2}^{\prime}+\rho_{1}^{\prime}+\eta\left(-\alpha u_{2}^{\prime \prime}+\rho_{12}^{\prime \prime}\right) \frac{\partial x_{2}}{\partial \eta}>0 .
\end{aligned}
$$

The total derivations can be found in Appendix B. $y_{1}$ has an unambiguously positive effect on the gift decision also when 1 receivies a gift himself. Hence,

Result 1. For a given social norm strength, richer individuals are more likely to reciprocate gifts and poorer to only receive.

This result is in line with empirical evidence from transition countries showing that the rich are involved in gift reciprocity networks to a larger extent than the poor (Kuehnast and Dudwick, 2004). If $y_{2}$ increases, the effect on 1's gift decision is ambiguous and depends on the dominating gift motive. In equivalence with (11), 2 will increase his gift to 1 when $y_{2}$ increases. Due to reciprocity, 1 will therefore feel more obliged to give to 2 , while the altruistic motive has the opposite effect, i.e., there is even less reason to give to 2 when he becomes richer. Hence, if gifts are dominated by the altruism part of impure altruism, the occurrence of gifts from 1 to 2 is decreasing in recipient income, while it is instead increasing if reciprocity is the dominating motive and is unaffected if the duty part of impure altruism is the only motive. Finally, a stronger social norm has an unambiguously positive effect on the gift decision.

In order to examine comparative statics concerning gift values when both $x_{1}^{*}>0$ and $x_{2}^{*}>0$, we have to consider the actions of 1 and 2 simultaneously as the exogenous variables change. By totally differentiating the first-order conditions in the D equilibrium, we obtain an equation system (which can be found in Appendix B) from which we derive the comparative statics. Below, we show the qualitative results: 


$$
\frac{\partial x_{1}^{*}}{\partial y_{1}}>0, \quad \frac{\partial x_{1}^{*}}{\partial y_{2}} \gtreqless 0, \quad \frac{\partial x_{1}^{*}}{\partial \eta}>0 .
$$

Once more, we find that individual 1 will increase his gift if $y_{1}$ increases or if the social norm becomes stronger. However, the effect on $x_{1}^{*}$ if $y_{2}$ increases is now ambiguous depending on the dominating gift motive. The impure altruism motive still predicts a weakly negative impact of $y_{2}$ on $x_{1}^{*}$, but due to reciprocity, the gift should increase in donor income. The reason is that when $y_{2}$ increases, 2 will increase his gift $x_{2}^{*}$, which 1 in turn will want to reciprocate by increasing $x_{1}^{*}$. Also these comparative statics results can be found in Table 2 below.

\subsection{Summary of comparative statics}

Table 2 presents a summary of the comparative statics described above. It is likely that the motives are present simultaneously, but in order to get clear effects that we can test in the empirical part, we present the signs of the comparative statics for each motive separately. We will keep these signs in mind when we, in Sections 4-6, empirically examine the gift motives.

Table 2: Summary of comparative statics for gifts $x_{1}^{*}$ from 1 to 2

\begin{tabular}{lccc|ccc} 
& \multicolumn{3}{c}{$P\left(x_{1}^{*}>0\right)$} & & \multicolumn{3}{c}{$x_{1}^{*} \mid x_{1}^{*}>0$} \\
$\begin{array}{l}\text { Dominating } \\
\text { transfer motive }\end{array}$ & $y_{1}$ & $\eta$ & $y_{2}$ & $y_{1}$ & $\eta$ & $y_{2}$ \\
\hline $\begin{array}{l}\text { Impure altruism, } \delta \\
\text { Reciprocity, } \rho\end{array}$ & + & + & - & + & + & - \\
& + & + & + & + & + & + \\
\hline
\end{tabular}

The variable whose predictions differ between the motives is recipient income, $y_{2}$. If gifts in society are predominantly given because of a norm of impure altruism, then one gives without expecting anything in return. The overall prediction is that gifts are more common and more sizable the lower the income of the recipient, even though the duty part predicts that 
recipient income has no effect. If, on the other hand, the dominating motive is a reciprocity norm, then one feels obliged to give to those who give. Hence, both the rate of occurrence and gift value increase in recipient income. We therefore concentrate on recipients when analyzing our data. In our model, the strength of social norms affects both gift motives, which means that we expect to find more gifts in communities where social norms are strong than where they are weak.

\section{Data and Social Norms Measures}

We base our empirical analysis on Romanian data from the 2003 Transfers and Social Capital Survey, ${ }^{15}$ which uses a nationally representative sample consisting of 2,641 households. Due to item non-respons for some questions, our sample is reduced to 2,311 households. ${ }^{16}$ For Romania, this is the first survey that looks carefully at the direction and the nature of inter-household transfers. Section 3.1 presents a detailed picture of gift transfers. One important feature of this data is the detailed information on social capital-related variables, which helps us construct the social norm proxies. We turn to these measures in Section 3.2. Besides inter-household transactions and social capital variables, the survey collects information on the standard socio-economic individual and household characteristics. Summary statistics can be found in Table 10, Appendix C.

\subsection{Inter-household gift transfers}

The questions on inter-household transfers are very detailed, i.e., In 2002, did you or a member of your household receive money from a person from another household?, and similarly for in-kinds such as food, clothes, etc. The same questions were asked for transfers given. If there was a transfer, the respondent answered whether it was: (1) A gift/for free, (2) A loan/exchange

\footnotetext{
${ }^{15}$ The survey was conducted as a part of the World Bank project Romania: Poverty Assessment.

${ }^{16}$ We drop households with missing information for household head education, age, income, health status, gifts, and/or social-capital related variables.
} 
of similar services, (3) An exchange (I received something different than what I gave, excluding money), or (4) A payment/sale. This careful categorization gives us a unique opportunity to disentangle pure gifts from other kinds of transfers.

In Romania, gifts are not only the most common form of inter-household transfer (94.5 percent of all households were involved in gift transfers, while 49 percent were involved in exchange and 50 percent in payment-like transfers), but they are also of higher value (on average) than other transactions (see also Amelina et al., 2004). We also have information about from/to whom transfers were received/given and the value of each transfer. ${ }^{17}$

Table 3 presents the occurrence of gifts. A total of 91.7 percent of the households had given some kind of gift to other households, 67.2 had received a gift, and 64.3 percent had both given and received.

Table 3: Gifts between households

\begin{tabular}{lrr}
\hline & $\begin{array}{r}\text { Number of } \\
\text { households }\end{array}$ & $\begin{array}{r}\text { Percent of the total sample } \\
(\mathrm{N}=2,311 \text { observations })\end{array}$ \\
\hline \hline Households giving gifts & 2,119 & 91.7 \\
Households receiving gifts & 1,552 & 67.2 \\
Households both giving and receiving gifts & 1,488 & 64.3 \\
Households neither giving nor receiving gifts & 128 & 5.5 \\
\hline
\end{tabular}

Before going any further, we need to emphasize some aspects to help us understand the large number of households involved in gift transfers. First, the questions about gifts do not require a minimum gift value, implying that even very small gifts are included. The questions are also very broad, covering money, free food products, meals, clothes, medical services, private lessons, help (for free) with daily housework activities (e.g., cleaning, cooking, minor repairs), transportation, etc. ${ }^{18}$

\footnotetext{
${ }^{17}$ The in-kind amounts represent the subjective evaluation of the respondent: What is the equivalent in money for this service/object?

${ }^{18}$ Most in-kind gifts involve food products, meals, and clothes. We therefore do not have to worry about potential problems in the estimation caused by a large fraction of time transfers (potentially affecting earned income). Only to a very small extent do in-kind gifts include help with agriculture, taking care of disabled people, etc.
} 
When we turn to value received, we note that gross receipts represent almost 12 percent of the recipient households' pre-transfer income, implying that private gifts are of real economic importance for Romanian households. ${ }^{19}$

The richness of the data provides a detailed picture of the gift flows in Romania. We observe a dense web of gifts among parents and children, brothers, aunts, neighbors, and friends. These relations are presented in Table 5. Unfortunately, we cannot infer anything about gifts within households, since transfers are recorded only between households. ${ }^{20}$

\footnotetext{
${ }^{19}$ The average gift value is about $1 / 3$ of the average social security transfers. Amelina et al. (2004) report that gift-giving flows in absolute terms are also five times higher than transfers through the Minimum Income Guarantee national social assistance program. Also note that the monthly median pre-transfer income at the household level was $4,250,000$ lei or about 130 USD.

${ }^{20} \mathrm{Co}$-residence is a common type of intergenerational transfer. In our data, nearly 40 percent of the households consist of at least one adult child, parent, and grandparent living together. It is commonly assumed that co-residence is based on the needs of the older persons, but research has shown that co-residence is typically mutually beneficial to both generations: "Now my only source of support is my father's pension. There are five of us in our family, and we all live off my father's pension,"in-depth interview, Amelina et al. (2004).
} 
Table 4: Gifts by relationship to the head of the respondent household $(\mathrm{N}=2,311)$

\begin{tabular}{ccccc|cccc}
\hline & \multicolumn{3}{c}{ Giving to } & \multicolumn{2}{c}{ Receiving from } & \multicolumn{2}{c}{ Giving to } & $\begin{array}{c}\text { In-kinds } \\
\text { Receiving from }\end{array}$ \\
\hline \hline & No.hh & $\begin{array}{c}\text { Median } \\
\text { Value }\end{array}$ & No.hh & $\begin{array}{c}\text { Median } \\
\text { Value } \\
(\text { lei })\end{array}$ & & No.hh & $\begin{array}{c}\text { Median } \\
\text { Value } \\
\text { (lei) }\end{array}$ & $\begin{array}{c}\text { No.hh } \\
\text { Median } \\
\text { Value } \\
(\text { lei })\end{array}$ \\
\hline \hline Parents & 98 & $2,000,000$ & 128 & $4,750,000$ & 336 & $1,550,000$ & 291 & $2,000,000$ \\
Children & 195 & $4,000,000$ & 151 & $2,000,000$ & 275 & $2,000,000$ & 304 & $1,250,000$ \\
Extended family & 321 & $1,000,000$ & 128 & $2,150,000$ & 727 & $1,000,000$ & 455 & 800,000 \\
Others & 466 & 500,000 & 86 & $1,000,000$ & 1,477 & 800,000 & 704 & 500,000 \\
\hline
\end{tabular}

Notes: Extended family category includes nephew/niece, brother/sister, grandfather/grandmother, un-
cle/aunt, and so on. Others include friends, neighbors, and co-workers.

$1 \mathrm{USD}=32,795$ ROL (Romanian lei) (WorldBank, 2003).

Table 5: Gifts by relationship to the head of the respondent household $(\mathrm{N}=2,311)$

\begin{tabular}{|c|c|c|c|c|c|c|c|c|}
\hline & \multicolumn{4}{|c|}{ Money } & \multicolumn{4}{|c|}{ In-kinds } \\
\hline & \multicolumn{2}{|c|}{ Donor } & \multicolumn{2}{|c|}{ Recipient } & \multicolumn{2}{|c|}{ Donor } & \multicolumn{2}{|c|}{ Recipient } \\
\hline & No.hh & $\begin{array}{c}\text { Median } \\
\text { Value } \\
\text { (lei) }\end{array}$ & No.hh & $\begin{array}{c}\text { Median } \\
\text { Value } \\
\text { (lei) }\end{array}$ & No.hh & $\begin{array}{c}\text { Median } \\
\text { Value } \\
\text { (lei) }\end{array}$ & No.hh & $\begin{array}{c}\text { Median } \\
\text { Value } \\
\text { (lei) }\end{array}$ \\
\hline Parents & 195 & $\overline{44,000,000}$ & 151 & $2,000,000$ & 275 & $2,000,000$ & 304 & $1,250,000$ \\
\hline Children & 98 & $2,000,000$ & 128 & $4,750,000$ & 336 & $1,550,000$ & 291 & $2,000,000$ \\
\hline Extended family & 321 & $1,000,000$ & 128 & $2,150,000$ & 727 & $1,000,000$ & 455 & 800,000 \\
\hline Others & 466 & 500,000 & 86 & $1,000,000$ & 1,477 & 800,000 & 704 & 500,000 \\
\hline
\end{tabular}

Notes: Extended family category includes nephew/niece, brother/sister, grandfather/grandmother, uncle/aunt, and so on. Others include friends, neighbors, and co-workers.

$1 \mathrm{USD}=32,795$ ROL (Romanian lei) (WorldBank, 2003).

Table 5 shows that in-kind gifts are more frequent than monetary gifts, while the (median) value of the monetary gifts is higher than of the inkind gifts. The highest values transferred are between parents and children. In particular, the (median) value of both monetary and in-kind gifts towards children (i.e., received from parents/given to children) are significantly larger than the corresponding gifts towards parents (i.e., received from children/given to parents). Gifts among others, e.g., neighbors and friends, even though more frequent, they have a lower (median) value when compared to parent-children gifts or to gifts among extended family.

Overall, it seems more likely for the households to give than to receive gifts. This is particularly true for gifts among extended family and among others. For these two categories, we also note that the reported values of in-kind gifts given are slightly higher than of the in-kinds received. This is a common finding in the literature usually referred to as recall bias, i.e., people tend to overstate their generosity (Cox et al., 2004; Kessler and Masson, 
Table 6: Gifts by relationship to the head of the respondent household $(\mathrm{N}=2,311)$

\begin{tabular}{|c|c|c|c|c|}
\hline & \multicolumn{2}{|c|}{ Monetary Gifts } & \multicolumn{2}{|c|}{ In-kind Gifts } \\
\hline & No.hh & $\begin{array}{c}\text { Median } \\
\text { Value } \\
\text { (lei) }\end{array}$ & No.hh & $\begin{array}{c}\text { Median } \\
\text { Value } \\
\text { (lei) }\end{array}$ \\
\hline \multicolumn{5}{|l|}{ Giving to } \\
\hline Parents & 98 & $2,000,000$ & 336 & $1,550,000$ \\
\hline Children & 195 & $4,000,000$ & 275 & $2,000,000$ \\
\hline Extended family & 321 & $1,000,000$ & 727 & $1,000,000$ \\
\hline Others & 466 & 500,000 & 1,477 & 800,000 \\
\hline \multicolumn{5}{|l|}{ Receiving from } \\
\hline Children & 128 & $4,750,000$ & 291 & $2,000,000$ \\
\hline Parents & 151 & $2,000,000$ & 304 & $1,250,000$ \\
\hline Extended family & 128 & $2,150,000$ & 455 & 800,000 \\
\hline Others & 86 & $1,000,000$ & 704 & 500,000 \\
\hline
\end{tabular}

Notes: Extended family category includes brother/sister, grandparents, nephew/niece, uncle/aunt, and so on. Others include friends, neighbors, and co-workers.

$1 \mathrm{USD}=32,795$ ROL (Romanian lei) (WorldBank, 2003)

1989). However, for monetary gifts, reported values received exceed reported values given. One possible explanation is that part of these receipts consists of remittances. Another possible explanation could be a form of recall bias, where one tends to overstate one's own low value gifts and mainly remember the most sizable receipts. However, when we regard the overall gifts (including both money and in-kinds, in all relations), the problem of over - or understated gifts should not be alarming.

\subsection{Social norms measures}

Given the non-experimental nature of our data, one of the most contentious issues is how to measure the strength of social norms, $\eta$. In what follows we construct two measures of social norm strength at the community level. ${ }^{21}$ This should be the relevant level, since almost 90 percent of the gifts occur between households in the same community.

Our first measure (hereafter social norms1) is the mean value at the community level of the following two statements: "Most people who live in

\footnotetext{
${ }^{21}$ In the present paper, community refers to the locality where the respondent lives. In our sample, the average number of observations at the community level is 50. Many localities form a county (judet), and many counties form a region. The Romanian territory is organized into 42 counties (judete), which in turn are organized into eight development regions (according to Romanian National Statistics).
} 
this village/neighborhood can be trusted," where the answers are 1-agree and 0-do not agree, and "Most people in this village/neighborhood are willing to help you if you need it," again with 1-agree and 0-do not agree implying that the measure can take on values between 0 and 2 . We believe that the extent to which people trust each other is a good proxy for the overall social norm strength. ${ }^{22}$ In addition, the second question captures the respondents' perception of their fellow villagers'/neighbors' willingness to help each other when it comes to critical times. Table 10 in Appendix $\mathrm{C}$ shows an average of this measure of 1.22 , with values varying from 0.76 to 1.75 .

One may argue that trust and perceived generosity may capture only some aspects of the community-wide social norms. Therefore, we also create a second measure (hereafter social norms2), which may capture social norms in a slightly different way, since it is linked to actual participation in the community associational life. More exactly, we use the community average answer to the following two questions: "During the last five years, did you participate with money or work in projects carried out in your community? (e.g., building a church),"with the answers 1-yes and 0-no, and "During the last two years, have you offered active support (not counting when you were paid to do so) to people who needed medical assistance, to elderly, or poor people, who are not related to you (a) through an organization or association or (b) through collaboration with the local government?", ${ }^{23}$ also with the answers 1 -yes and $0-$ no. This measure is likely to capture some internalized social norms concerning gift behavior (see e.g., Portes, 1998). ${ }^{24}$ We believe that in communities with strong social norms, people are more likely to make resources available (to church or other households, not necessarily related through kinship or friendship ties). The average of this measure is 0.65 , varying from 0.31 to 1.25 .

The correlation between social norms1 and social norms2 is 0.44 and statistically significant at the 1 percent level. Hence, we expect the two

\footnotetext{
${ }^{22}$ In a recent review, Keefer and Knack (2008) provide evidence on the strong link between social norms and trust as two fundamental components of social capital.

${ }^{23}$ Note that direct support to close and extended family is not included.

${ }^{24}$ Also Guiso et al. (2004) talk about donations to charity as motivated by strongly internalized norms.
} 
measures to have similar effects in the regressions, but due to the somewhat different nature of the two, we may gain some insights by considering them separately. To complement these measures and test the robustness of our results, we will also test some alternative proxies in our empirical analysis.

\section{Empirical estimates}

According to the comparative statics in Table 2, our variables of interest when identifying the structural equations for determining gift behavior are the recipient and donor household pre-transfer income and the strength of the social norm. As most of the previous studies on private transfers, we only have information on either donor or recipient income in connection to any given gift, which could result in an omitted variable bias. We return to this issue in Section 4.3. Since recipient income varies in its predictions (contrary to donor income), we focus on gross recipients in the following analysis. ${ }^{25}$

\subsection{Specification}

Our empirical approach is as follows: We start by fitting a probit for the gross recipient households, and then study the amounts received, conditional on having received a gift. The latent variable underlying the gross receipts for the $i$ th household can be described by the reduced form equation

$$
T_{i v}^{*}=\alpha_{0}+\alpha_{1} Y_{i v}+\alpha_{2} \eta_{v}+\beta^{\prime} X_{i v}+\delta^{\prime} H_{v}+\varepsilon_{i v}
$$

where $Y_{i v}$ is the recipient household income; $\eta_{v}$ reflects the average social norm strength in community $v ; X_{i v}$ is a vector including respondent individual/household characteristics such as age, gender, education, health, family size, and number of children younger than 18; and $H_{v}$ is a vector of village/community $v$ characteristics such as size of the community in terms of

\footnotetext{
${ }^{25}$ We have also considered the gross donors and found that donor income has a significantly positive effect on both the probability of giving and the value given. The results (available upon request) are thus in line with our comparative statics results and are compatible with both gift motives.
} 
population, average consumption at the community level, etc. Finally, $\varepsilon_{i v}$ is a normally distributed error term with mean 0 and variance $\sigma_{v}$. We do not observe the latent variable $T_{i v}^{*}$ but only whether the recipient household received a transfer, i.e., $T_{i v}^{*}>0$. The above probit model will be estimated correcting for heteroskedasticity and clustering the residuals at the community level.

Next, if household $i$ receives a gift, the amount received, $T_{i v}$, is estimated using an OLS on the restricted sample:

$$
T_{i v}=\beta_{0}+\beta_{1} Y_{i v}+\beta_{2} \eta_{v}+\varsigma^{\prime} X_{i v}+\xi^{\prime} H_{v}+\left(u_{i v} \mid T_{i v}>0\right),
$$

where $u_{i v}$ is a random error component. Note that the gift received, $T_{i v}$, is measured as the value of all money and in-kind gifts received by the household.

Previous studies have found different effects depending largely on the estimation method. Some have estimated negative effects of recipient income on the amount received using a Tobit model (e.g., Altonji et al., 1997; Schoeni, 1997) while others have estimated a positive effect using a generalized Tobit (Heckit) estimation (e.g., Cox, 1987; Cox and Jakubson, 1995). Besides not being robust to non-normal errors, a Tobit model assumes that the signs of the coefficients in the transfer probability and in the transfer amount equations are the same. A major drawback with the two-stage Heckman model is the sensitivity of the estimates to the identification restrictions. ${ }^{26} \mathrm{An}$ adequate identification of the parameters is achieved when finding a variable that influences the probability of receiving but not the value received. This task remains arduous in this context.

Some studies use a non-linear specification to test the relationship between recipient income and private transfers, i.e., allowing for different motives depending on recipient income (Cox et al., 2004; Kazianga, 2006). Similar to this line of thought, in Section 5 we analyze gifts to the rich and to the poor separately, hypothesizing that different motives may be dominating

\footnotetext{
${ }^{26}$ This estimation will solve the problem of proportionality but is still not robust to non-normality.
} 
for the two groups following our Result 1 in Section 2.2.

\subsection{Gifts received}

Estimates of the probit equation for the gross recipients are presented in Table 7, Columns 1 and 2. The dependent variable takes the value 1 if the respondent declared that the household received a gift (money or in-kind) during the last year, and 0 otherwise.

We observe that recipient income has a positive and significant effect on the probability of receiving gifts. The marginal effect of the probit for the social norms1 is positive and significant at the 10 percent level. As explained in Section 3, we also use a second definition of social norms, i.e., social norms2. ${ }^{27}$ As is clear from Column 2, social norms measured in this way also have a positive and statistically significant effect on the probability of receiving a gift. ${ }^{28}$

The probability of receiving a gift follows a U-shaped profile over the lifecycle, consistent with previous findings (e.g., Cox et al., 1998). Unlike some studies for developing countries (Cox et al., 1998; Lucas and Stark, 1985; Cox et al., 2004, for Peru, Botswana, and the Philippines, respectively), but similar to Cox et al. (1997) for a transition country, i.e., Poland, household head gender does not influence the probability of receiving gifts. Also, we find that health status and education of the household head are not statistically significant. As family size increases, the probability of receiving a gift from another household decreases. Since we separately control for number of children younger than 18 , one possible explanation for this negative correlation

\footnotetext{
${ }^{27}$ One possible concern is the fact that we measure social norms at the community of the receiver, while, of course, the norms at the community of the giver should matter. Thanks to the richness of our data we are able to check the location of the giver (whether within the same community as the receiver, other community or abroad), given that the household has received a gift. Overall, almost 90 percent of the gift transfers occur among households within the same community.

${ }^{28}$ Since integrating social norm measures with private transfers is a new empirical exercise, we also check whether our results are robust with respect to other social norm proxies, e.g., "In case of a problem that concerns many members of the community, what do you most often do? (a) do nothing (b) try to solve it alone (c) try to solve it together with others." The results (available upon request) are fairly robust.
} 
Table 7: Gross Gifts Received

\begin{tabular}{|c|c|c|c|c|}
\hline & \multicolumn{2}{|c|}{ Probit $^{a}$} & \multicolumn{2}{|c|}{$\mathrm{OLS}^{b}$} \\
\hline & [1] & {$[2]$} & {$[3]$} & {$[4]$} \\
\hline \multirow[t]{2}{*}{ Private pre-transfer income } & $\overline{.0003^{* *}}$ & $.0003^{* *}$ & $.068^{* * *}$ & $.068^{* * *}$ \\
\hline & $(.0001)$ & $(.0001)$ & $(.017)$ & $(.017)$ \\
\hline \multirow[t]{2}{*}{ Social norms1 } & $.168 *$ & & $7.323^{*}$ & \\
\hline & $(.100)$ & & $(4.228)$ & \\
\hline \multirow[t]{2}{*}{ Social norms2 } & & $.243^{* *}$ & & $13.193^{* *}$ \\
\hline & & $(.101)$ & & $(5.424)$ \\
\hline \multirow[t]{2}{*}{ Female } & .029 & .027 & -4.175 & -4.425 \\
\hline & $(.022)$ & $(.022)$ & $(2.706)$ & $(2.725)$ \\
\hline \multirow[t]{2}{*}{ Age } & $-.016^{* * *}$ & $-.015^{* * *}$ & $-2.071^{* * *}$ & $-2.047 * * *$ \\
\hline & $(.004)$ & $(.004)$ & $(.654)$ & $(.649)$ \\
\hline \multirow[t]{2}{*}{$\mathrm{Age}^{2}$} & $.0001^{* * *}$ & $.0001^{* * *}$ & $.019 * * *$ & $.018^{* * *}$ \\
\hline & $(.0001)$ & $(.0001)$ & $(.006)$ & $(.006)$ \\
\hline \multirow[t]{2}{*}{ Health } & -.035 & -.032 & 3.541 & 3.815 \\
\hline & $(.028)$ & $(.024)$ & $(2.502)$ & $(2.535)$ \\
\hline \multirow[t]{2}{*}{ Household size } & $-.057 * * *$ & $-.057 * * *$ & -1.187 & -1.250 \\
\hline & $(.010)$ & $(.015)$ & $(.957)$ & $(.946)$ \\
\hline \multirow[t]{2}{*}{ Children under 18} & $.065^{* * *}$ & $.063^{* * *}$ & .031 & .058 \\
\hline & $(.017)$ & $(.017)$ & $(1.782)$ & $(1.773)$ \\
\hline \multirow[t]{2}{*}{ Secondary school } & .004 & .0001 & -1.897 & -2.237 \\
\hline & $(.039)$ & $(.039)$ & $(3.721)$ & $(3.803)$ \\
\hline \multirow[t]{2}{*}{ Technical/High school } & .026 & .032 & -2.618 & -2.559 \\
\hline & $(.041)$ & $(.041)$ & $(3.720)$ & $(3.695)$ \\
\hline \multirow[t]{2}{*}{ Post high school } & -.016 & -.009 & -4.152 & -4.105 \\
\hline & $(.047)$ & $(.047)$ & $(3.272)$ & $(3.239)$ \\
\hline \multirow[t]{2}{*}{ University } & .022 & .023 & 5.507 & 5.470 \\
\hline & $(.056)$ & $(.055)$ & $(9.306)$ & $(9.262)$ \\
\hline \multirow[t]{2}{*}{$\ln (\mathrm{pop})$} & .004 & .016 & $1.787^{* *}$ & $2.504^{* * *}$ \\
\hline & $(.013)$ & $(.015)$ & $(.795)$ & $(.874)$ \\
\hline \multirow{2}{*}{$\begin{array}{l}\text { Average consumption } \\
\text { in community }\end{array}$} & .0006 & -.0007 & -.004 & -.010 \\
\hline & $(.001)$ & $(.001)$ & $(.052)$ & $(.056)$ \\
\hline \multirow[t]{2}{*}{ Northeast } & $-.137^{* *}$ & $-.182^{* *}$ & .602 & -1.851 \\
\hline & $(.071)$ & $(.072)$ & $(1.328)$ & $(2.187)$ \\
\hline \multirow[t]{2}{*}{ Southeast } & -.057 & -.082 & $9.340^{*}$ & 7.807 \\
\hline & $(.065)$ & $(.075)$ & $(5.321)$ & $(4.845)$ \\
\hline \multirow[t]{2}{*}{ Center } & $-.168^{* *}$ & $-.182^{* *}$ & 1.094 & .128 \\
\hline & $(.070)$ & $(.075)$ & $(2.467)$ & $(2.261)$ \\
\hline \multirow[t]{2}{*}{ Southwest } & -.011 & -.012 & $4.812^{*}$ & $4.942^{*}$ \\
\hline & $(.066)$ & $(.062)$ & $(2.808)$ & $(2.679)$ \\
\hline Northwest & -.037 & -.070 & .348 & -1.475 \\
\hline & $(.068)$ & $(.079)$ & $(1.718)$ & $(2.207)$ \\
\hline West & -.034 & -.005 & $-4.077^{*}$ & -3.224 \\
\hline & $(.055)$ & $(.057)$ & $(2.392)$ & $(2.227)$ \\
\hline Bucharest & $-.233^{* * *}$ & $-.242^{* * *}$ & -1.708 & -2.276 \\
\hline & $(.071)$ & $(.085)$ & $(6.573)$ & $(7.261)$ \\
\hline Number of observations & 2,311 & 2,311 & 1,225 & 1,225 \\
\hline Pseudo $R^{2}$ or $R^{2}$ & .05 & .05 & .05 & .05 \\
\hline $\begin{array}{l}{ }^{a} \text { Dependent variable }=1 \text { if } \\
\text { marginal effects calculated }\end{array}$ & $\begin{array}{l}\text { respond } \\
\text { the meal }\end{array}$ & t received & gift; & \\
\hline${ }^{b}$ Dependent variable $=$ the & alue receiv & , conditio & al on receivi & \\
\hline $\begin{array}{l}\text { Notes: All values are expres } \\
\text { variables, see Table } 10, \text { App } \\
\text { skedasticity and clustering o } \\
\text { and } * * * \text { denote significance }\end{array}$ & in millic & $\begin{array}{l}\text { lei. For a } \\
\text { errors are }\end{array}$ & $\begin{array}{l}\text { escription o } \\
\text { corrected fo } \\
\text { imunity lev }\end{array}$ & $\begin{array}{l}\text { all the other } \\
\text { hetero- } \\
*, * *\end{array}$ \\
\hline
\end{tabular}


could be related to co-residency, which in itself is a kind of intergenerational transfer. Co-residency also implies a possibility of resource pooling and risk sharing. ${ }^{29}$

To eliminate any suspicion that our social norm proxies may capture other regional differences, we control for eight regional indicators corresponding to the following regions: Northeast, Southeast, Center, Southwest, Northwest, West, Bucharest, and South (the reference). ${ }^{30}$ The regional indicators show that the likelihood of receiving gifts is lower in Northeast, Center, and Bucharest compared to in South. The results regarding social norm measures are, however, similar also when we exclude regional indicators.

Let us now summarize our findings so far in relation to the predictions in Table 2: We find that the strength of social norms increases the probability of receiving a gift, which indicates that social norms are indeed important for the occurrence of gifts. The fact that social norms are significant supports both the reciprocity motive and impure altruism. Recipient income is positive and also statistically significant, which is consistent with reciprocity. Hence, our estimates so far suggest reciprocity as the dominating transfer motive.

Next, we focus on the values received conditional on having received a gift. The OLS estimates on the restricted sample are presented in Table 7, Columns 3 and $4 .{ }^{31}$ We find that values received increase in recipient income.

\footnotetext{
${ }^{29}$ Another interpretation and a possible concern when it comes to household size could be that it is not unusual for some household members to work in other cities or abroad and send remittances (in the form of gifts) back home. We do not attempt to control for this possible endogeneity problem, but do signal that the coefficient associated with family size should be interpreted as a correlation, since we can not establish a causal link. However, 80 percent of the employed household members worked in the city where they lived.

${ }^{30}$ There are geographical, cultural and economic disparities among these regions. E.g., Bucharest, Center, and West are the richest regions and Northeast is the poorest according to the Romanian National Statistics.

${ }^{31}$ Alternatively, we have estimated this equation using a Tobit regression. The results (available upon request) came out pretty similar. Also, we have estimated a Heckit model to control for possible bias selection. The probit equation used to generate the Mills ratio contains the same explanatory variable as in Table 7 , plus some interaction terms between income, age, and gender. Additionally, we have used a spline specification for income. Of course, we recognize that this specification is not fully satisfactory. However, when doing so, the results turned out very similar to the ones we attained when using Tobit and OLS
} 
Also, both social norm strength proxies turn out positive and significant. Hence, also the OLS estimates of the gift values point to the reciprocity norm as the dominating gift motive. Quite interestingly, when studying the values received, we note that covariates like gender, household size, and education are not statistically significant. This could also be interpreted as evidence of norms, traditions, and customs being important, rather than household characteristics.

\subsection{Measure of income}

As we have already mentioned, one possible concern is that both the recipient and the donor incomes enter the transfer function according to our model presented in Section 2, while our data only contains information about one of them at a time. This could result in an omitted variable bias, whose sign and size depend on the correlation between the recipient and the donor incomes. However, Kazianga (2006) for Burkina Faso and Cox and Jakubson (1995) and Cox and Rank (1992) for the U.S. find only a small positive bias from omitting donor income. While we do not pursue any analytical derivation of the bias, we do attempt to find a proxy for donor income. Let us consider a simple exercise where we only look at transfers among neighbors, since according to Table 5 most of the gifts are made in the Others category. We therefore use the mean income at the county level as a proxy for donor income. ${ }^{32}$ In doing so, the results (available upon request) are qualitatively similar to the ones found in Table 7 , and, in line with our theoretical predictions, donor income is positive and statistically significant. ${ }^{33}$ Thus, this exercise suggests that the dominant transfer motive (among neighbors) is indeed the reciprocity norm.

\footnotetext{
on the selected sample.

${ }^{32}$ The average county income could be a good proxy when we only consider neighbors, since in this case we know that recipients and donors live geographically close. The average county income is available from Romanian National Statistics.

${ }^{33}$ More exactly, in the probit estimations, both recipient and donor income, and also social norms, turn out positive and statistically significant. However, when we estimate the OLS, both recipient and donor incomes are still positive and significant, while our social norm proxies become statistically insignificant.
} 
It is widely recognized that especially in rural developing countries, selfreported income is likely to include errors. We therefore alternatively proxy our income measure with a consumption measure, and the results remain fairly robust. Hence, the quality of our income data seems sufficient.

\section{Different motives behind gifts to the poor and the rich?}

One interesting feature of the Romanian society that we also observe in our data is that (although income has a small positive effect on receipts as seen in Table 7) people in all income groups are likely to receive; e.g., 70 percent in the lowest quartile, 65 percent between the lower and upper quartiles, and 67 percent in the upper quartile received gifts. Moreover, according to our theoretical model, recipient income affects both the likelihood of receiving and the value received differently depending on the dominating gift motive. More exactly, gifts weakly decrease with recipient income if the impure altruism is the dominating gift motive, while they increase if reciprocity is dominating. Also, a more specific prediction of the model is that the rich are more likely to be motivated by the reciprocity norm than the poor. Therefore, we test whether the two norms, reciprocity and impure altruism, are of different importance for gifts to people in different income segments; our prior is that for the rich, the reciprocity norm is relatively more important than for the poor, who, in turn, may still receive due to norms of impure altruism even if they may not be able to afford to be part of reciprocal networks to the same extent as the rich. ${ }^{34}$

Thus, in Table 8 we consider both the likelihood of receiving a gift and the values received separately for the (relatively) poor and the (relatively) rich. More exactly, we compute income quartiles for each community, and then split the sample between the households in the 1st (lower) quartile (Column

\footnotetext{
${ }^{34}$ This reasoning is also in line with in-depth interviews that acknowledge that it is becoming increasingly difficult for the poor to stay involved in reciprocal networks: "If you cannot rise up to a certain level, you are pushed aside. You cannot access their (i.e. the rich) circles." (in-depth interview, Amelina et al., 2004).
} 
1 for the probit and Column 3 for the OLS) and those in the upper three quartiles (Column 2 for the probit and Column 4 for the OLS). Each cell reports the estimates of our main variables of interest - recipient's income and social norms - while we control for all other characteristics included in Table 7 . In the upper part of Table 8 we use social norms 1 and in the lower social norms2 to proxy for social norm strength.

Table 8: Gross gifts received for the poor and the rich

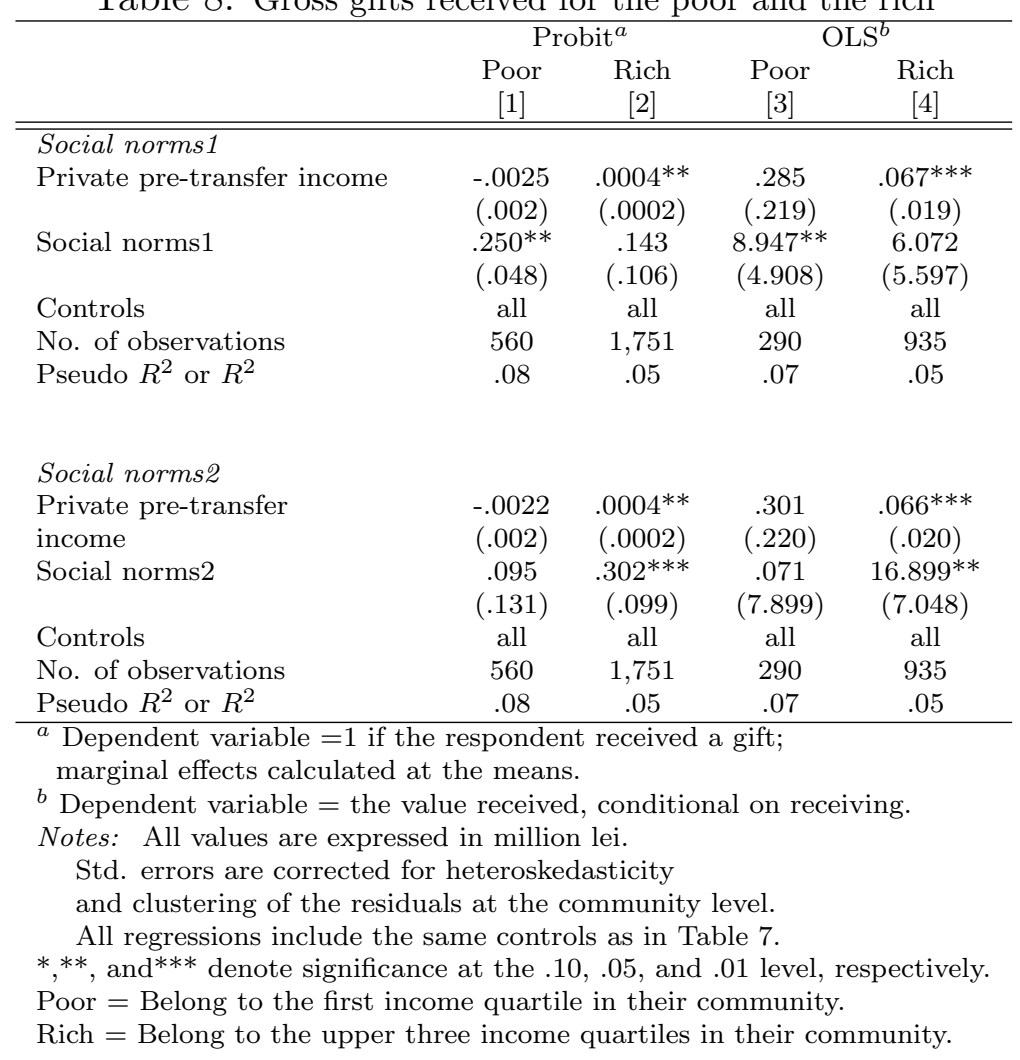

As seen in Table 8, social norm strength affects both the gift probability and value for both rich and poor. Although social norms1 and social norms2 are correlated, they obviously capture different features of social norm strength, thereby affecting gifts to the rich and the poor differently, a matter we discuss further below.

Before that, we note that income has no significant effect on poor households' likelihood of receiving gifts or on the values received, while for the 
rich, higher income implies both higher likelihood of receiving and larger values received. Hence, our results so far suggest that middle- and high-income households may receive mainly due to the reciprocity norm, while impure altruism seems to play a role for gifts to the relatively poor. That could be either because the duty part of impure altruism is dominating, or because impure altruism and reciprocity are simultaneously present and imply counteracting effects from recipient income.

To further explore the results concerning the poor, we next consider different definitions of poor (and rich, respectively). Thus, for each community we define the households whose income belongs to the lowest decile as poor (and thus the upper 9 deciles as rich). Our results (not reported) show that income is now negative and significant at the 1 percent level, and social norms 1 is positive and significant for the poor. ${ }^{35}$ Hence, when we consider the very poorest, the impure altruism norm seems to be more important relative to the reciprocity norm. We obtain similar results when we consider the bottom two deciles. However, when we instead consider the median as the division between rich and poor, the results are similar to those in Table 8 for the poor. ${ }^{36}$ The results for the rich are the same as in Table 8 regardless of the definition, so the reciprocity norm seems to be dominating for gifts to those with an income higher than the median in their community.

That the two social norm proxies have different impact on gifts to the rich and to the poor is perhaps not as surprising as it may first seems. Social norms1 indicates trust among people in the community and perceived willingness to help those within close proximity, so it may particularly reflect impure altruism at the community level. ${ }^{37}$ Social norms2, on the other hand, is more related to participation in the community associational life and active involvement in solving problems jointly with others. Amelina et al. (2004) and Howard (2003) find that in transition countries, wealthier house-

\footnotetext{
${ }^{35}$ One possible concern at this point is that we have much less variation in the lowest decile. However, since we make the division at the community level and given the high income heterogeneity between communities, this is of less concern: the mean pre-transfer income is 10.842 million lei, (std.dev. is 6.836 million lei).

${ }^{36}$ All these results are available upon request.

${ }^{37}$ Of course, given the nature of our data, we need to be cautious about strong conclusions when it comes to the "true" measurement of these proxies.
} 
holds tend to be more involved in the community associational life. This can explain why social norms2 turns out significant for the rich but not for the poor.

Thus, overall, we may conclude that the dominating gift motives for gifts to the poor and to the rich indeed differ. For the middle- and high-income households, the dominant transfer motive seems to be the reciprocity norm. For the poor, on the other hand, we are not able to single out one dominating motive; however, the lower the income, the stronger the relative importance of the impure altruism seems as compared to the reciprocity norm.

\section{Money vs. in-kind gifts}

Table 5 showed that receiving in-kind is more frequent than receiving monetary gifts. This was not surprising since in , e.g., important traditions and religious ceremonies, the in-kind gifts are more important than monetary gifts. Social norms showed to be important for over-all gifts but if especially in-kinds are given due to tradition and religion, we expect them to be more influenced by social norms than monetary gifts. Thus, we next separate gifts into money and in-kind and investigate whether the motives differ between these two gift categories.

Table 9 show the estimated probability of receiving the two kinds of gifts, respectively (Columns 1 and 2 in the left and right part) and OLS on the restricted samples who actually received in-kinds (or money) (Columns 3 and 4). In each regression, the controls include all individual and community characteristics from Table 7 .

We note that social norm strength is indeed more important for in-kind than for monetary gifts as we hypothesized. In particular, our results from the left-hand part of Table 9 suggest reciprocity as the dominating transfer motive for the in-kind gifts. ${ }^{38}$ Although recipients with higher income receive larger monetary gifts, the effects from social-norm strengths ar not significant, so we cannot conclude that monetary gifts as such are due to any

\footnotetext{
${ }^{38}$ Hann (2006) is also discussing the importance of reciprocity norm when it comes to in-kind gifts in Romania.
} 
Table 9: Gross In-Kind and Monetary Gifts Received

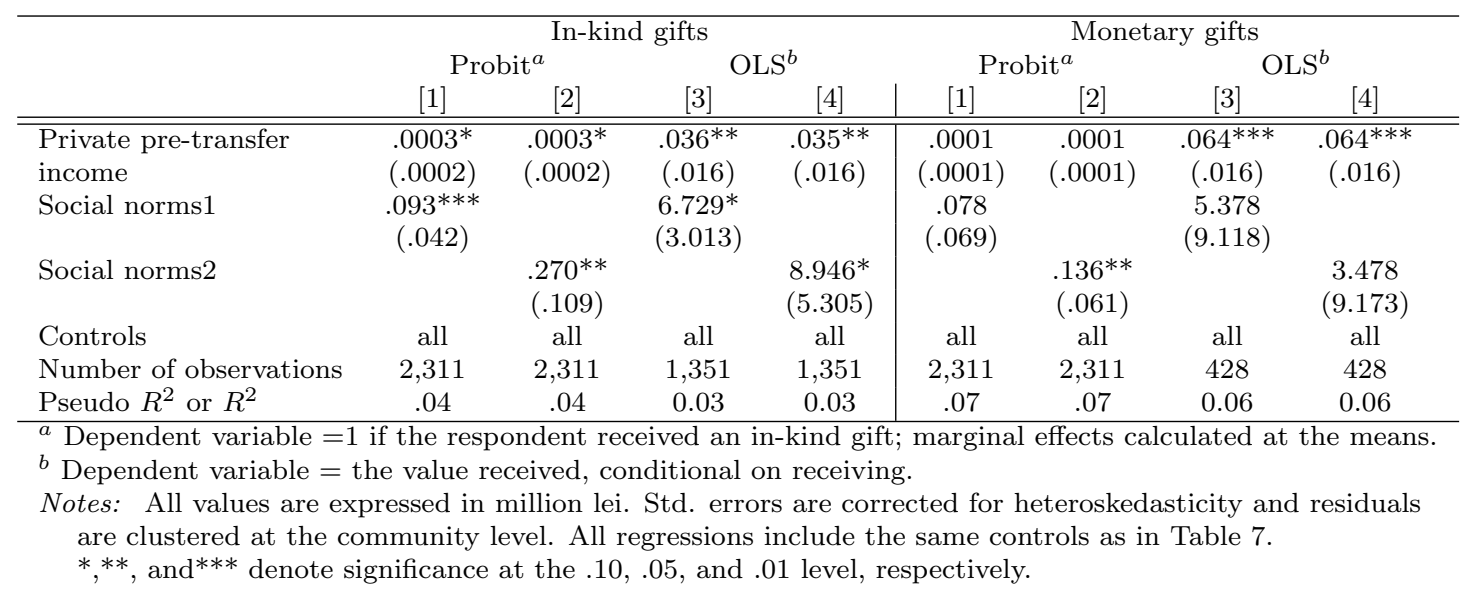

social norms.

We also saw in Table 5 that in-kind transfers are more common among the extended family and among, e.g., neighbors and friends, while monetary gifts are more common between parents and children. Therefore, we consider separately the two kinds of transfers among parents and children, on the one hand, and among neighbors, friends, and extended family, on the other to see whether the relationship between donor and recipient affects the motive. The effects are actually quite robust irrespective of donor-recipient relation and consistent with the reciprocity norm for in-kind gifts, while they remain inconclusive for monetary gifts. ${ }^{39}$ Hence, we find

\section{Conclusions}

In this paper we have studied private gift transfers. Thanks to our unusually rich data, we were able to isolate pure gifts from informal loans and exchangerelated transfers.

\footnotetext{
${ }^{39}$ These results are available upon request. One possible concern for the parent-children probits is that we do not know whether a non-receiving household has any children/living parents or not.
} 
We formulated a simple but illustrative theoretical model in which social norms related to impure altruism and reciprocity motivate the act of gift giving. We test these motives on data from Romania, a country where gift transfers are very frequent among both the rich and the poor.

In our empirical analysis, we find that recipient income increases both the likelihood of receiving and the value received. Moreover, we find that the strength of social norms at the community level is important for gift behavior among Romanians. Hence, in light of our theoretical predictions, the dominating gift motive seems to be the reciprocity norm. We also analyze the poor and non-poor separately. When doing so, we find that the reciprocity norm is the dominating motive for middle- and high-income households. Even though the poorest households receive to the same extent as the rich, why they receive is less clear, i.e., both the reciprocity and the impure altruism norms may matter, or they may receive because there is a duty norm to give to the poor. Moreover, the lower the income, the stronger the relative importance of the impure altruism seems as compared to the reciprocity norm.

Since our gift data is very rich, we also have information on the kind of gift received. When analyzing monetary and in-kind gifts separately, we also find differences. For in-kind gifts, social norm strength in the community plays an important role, while this is not so for monetary gifts. Overall, it seems that the in-kind gifts are mainly motivated by reciprocity norms in the community, while the results are less clear for the monetary gifts. One explanation for this result might be that traditions and customs primarily require in-kind gifts.

Our analysis was only concerned with short-run effects. The theoretical model in this paper is static, and our data contains economic activities during one single year. One could, though, imagine that social norms concerning private transfers change over time, possibly due to a country's economic situation. Romania has, for many years, had problems with poverty. In the presence of poverty and with, e.g., low public pensions, one could perhaps regard it as natural that people try to help each other and that this has developed into a norm. It is therefore plausible that an economy-wide economic improvement could decrease this need and in the long run also affect social 
norms regarding private transfers. A task for future research would therefore be to analyze the long-run effects of endogenous social norms on gift giving. 


\section{References}

Altonji, J. G., Hayashi, F., and Kotlikoff, L. J. (1997). Parental altruism and inter vivos transfers: Theory and evidence. Journal of Political Economy, 105(6):1121-1166.

Amelina, M., Chiribuca, D., and Knack, S. (2004). Mapped in or mapped out? The Romanian poor in inter-household and community networks. The World Bank.

Anghelescu, S. (1999). Agon. Tensiunea fundamentala a riturilor de trecere. Editura Ex Ponto.

Brekke, K. A., Kverndokk, S., and Nyborg, K. (2003). An economic model of moral motivation. Journal of Public Economics, 87:1967-1983.

Cai, F., Giles, J., and Meng, X. (2006). How well do children insure parents against low retirement income? An analysis using survey data from urban China. Journal of Public Economics, 90:2229-2255.

Cassar, A., Crowley, L., and Wydick, B. (2007). The effect of social capital on group loan repayment: Evidence from field experiments. The Economic Journal, 117:F85-F106.

Cox, D. (1987). Motives for private income transfers. Journal of Political Economy, 95(3):508-546.

Cox, D., Eser, Z., and Jimenez, E. (1998). Motives for private transfers over the life cycle: An analytical framework and evidence for Peru. Journal of Development Economics, 55(1):57-80.

Cox, D., Hansen, B., and Jimenez, E. (2004). How responsive are private transfers to income? Evidence from a laissez-fair economy. Journal of Public Economics, 88:2193-2219.

Cox, D. and Jakubson, G. (1995). The connection between public transfers and private interfamily transfers. Journal of Public Economics, 57(1):129167.

Cox, D., Jimenez, E., and Okrasa, W. (1997). Family safety nets and economic transition: A study of worker households in Poland. Review of Income and Wealth, 43(2):191-209.

Cox, D. and Rank, M. R. (1992). Inter-vivos transfers and intergenerational exchange. Review of Economics and Statistics, 74(2):305-314. 
Dufwenberg, M. and Kirchsteiger, G. (2004). A theory of sequential reciprocity. Games and Economic Behavior, 47:268-298.

Fafchamps, M. (1992). Solidarity networks in preindustrial societies: Rational peasants with a moral economy. Journal of Development Economics, $71: 261-287$.

Fafchamps, M. and Lund, S. (2003). Risk-sharing networks in rural Philippines. Economic Development and Cultural Change, 41:1-34.

Fehr, E. and Falk, A. (2002). Psychological foundations of incentives. Eoropean Economic Review, 46:687-724.

Fehr, E. and Gächter, S. (2000). Fairness and retaliation: The economics of reciprocity. Journal of Economic Perspectives, 14(3):159-181.

Fischer, P. and Huddart, S. (2008). Optimal contracting with endogenous social norms. American Economic Review, 98(4):1459-1475.

Guiso, L., Sapienza, P., and Zingales, L. (2004). The role of social capital in finacial development. The American Economic Review, 94(June):526-556.

Hann, C. (2006). The gift and reciprocity: Perspectives from economic anthropology. In Kolm, S.-C. and Ythier, J. M., editors, Handbook of the Economics of Giving, Altruism and Reciprocity. Elsevier.

Howard, M. M. (2003). The weakness of cvil society in post-communist europe. Cambridge University Press.

Kazianga, H. (2006). Motives for household private transfers in Burkina Faso. Journal of Development Economics, 79(1):73-117.

Keefer, P. and Knack, S. (2008). Social capital, social norms and the new institutional economics. In Menard, C. and Shirley, M. M., editors, Handbook of New Institutional Economics. Springer.

Kessler, D. and Masson, A. (1989). Bequest and wealth accumulation: Are some pieces of the puzzle missing? Journal of Economic Perspectives, $3(3): 141-152$.

Kligman, G. (1988). The wedding of the dead: Ritual, Poetics, and Popular Culture in Transylvania. University of California Press.

Kolm, S.-C. (2006). Reciprocity: Its Scope, Rationales and Consequences. In Kolm, S.-C. and Ythier, J. M., editors, Handbook of the Economics of Giving, Altruism and Reciprocity. Elsevier. 
Kuehnast, K. and Dudwick, N. (2004). Better a hundred friends tha a hundred rubles? social networks in transition - the Kyrgyz Republic. The World Bank.

Lindbeck, A., Nyberg, S., and Weibull, J. W. (1999). Social norms and economic incentives in the welfare state. Quarterly Journal of Economics, 114(1):1-35.

Lucas, R. E. and Stark, O. (1985). Motivations to remit: Evidence from Botswana. Journal of Political Economy, 93(5):901-918.

Mauss, M. (1954). The Gift. Routledge, 2002.

Osborne, M. and Rubinstein, A. (1994). A Course in Game Theory. The MIT Press.

Platteau, J.-P. (2006). Solidarity norms and institutions in village societies: Static and dynamic considerations. In Kolm, S.-C. and Ythier, J. M., editors, Handbook of the Economics of Giving, Altruism and Reciprocity. Elsevier.

Platteau, J.-P. and Sekeris, P. G. (2007). On the feasibility of power and status ranking in traditional setups. mimeo, University of Namur.

Pop, M. (1999). Obiceiuri Traditionale Romanesti. Editura Univers.

Portes, A. (1998). Social capital: Its origins and applications in modern sociology. Annual Review of Sociology, 24:1-24.

Rabin, M. (1993). Incorporating fairness into game theory and economics. American Economic Review, 83(5):1281-1302.

Ravallion, M. and Dearden, L. (1988). Social security in a "moral economy": An empirical analysis for Java. Review of Economics and Statistics, $70(1): 36-44$.

Sacco, P. L., Vanin, P., and Zamagni, S. (2006). The economics of human relationships. In Kolm, S.-C. and Ythier, J. M., editors, Handbook of the Economics of Giving, Altruism and Reciprocity. Elsevier.

Schechter, L. (2007). Theft, gift-giving, and trustworthiness: Honesty is its own reward in rural Paraguay. American Economic Review, 97(5):15601582. 
Schoeni, R. F. (1997). Private interhousehold transfers of money and time: New empirical evidence. Review of Income and Wealth, 43(4):423-448.

Schokkaert, E. (2006). The empirical analysis of transfer motives. In Kolm, S.-C. and Ythier, J. M., editors, Handbook of the Economics of Giving, Altruism and Reciprocity. Elsevier.

Seinen, I. and Schram, A. (2006). Social status and group norms: Indirect reciprocity in a repeated helping experiment. European Economic Review, 50(3):581-602.

Sugden, R. (1984). Reciprocity: The supply of public goods through voluntary contributions. Economic Journal, 94(376):772-787.

Vaduva, O. (1997). Magia Darului. Editura Enciclopedica.

WorldBank (2003). Romania poverty assessment. 


\section{A Appendix: Proofs}

\section{A.1 Proof that Assumption 1 is sufficient to assure that $\frac{d x_{1}}{d x_{2}}<1$}

Proof. The first-order condition (4) for individual 1 in the fully interior solution where $x_{1}^{*}>0$ and $x_{2}^{*}>0$ reads:

$$
-u_{1}^{\prime}+\eta\left(v_{x_{1}}^{\prime}+\alpha u_{2}^{\prime}+\rho_{1}^{\prime}\right)=0
$$

If 1 takes $x_{2}^{*}$ as given, and we differentiate (21) w.r.t $x_{1}$ and $x_{2}$, we can write

$$
\frac{d x_{1}}{d x_{2}}=\frac{u_{1}^{\prime \prime}+\eta\left(\alpha u_{2}^{\prime \prime}-\rho_{12}^{\prime \prime}\right)}{u_{1}^{\prime \prime}+\eta\left(v_{x_{1}}^{\prime \prime}+\alpha u_{2}^{\prime \prime}+\rho_{11}^{\prime \prime}\right)}>0
$$

Hence, $\frac{d x_{1}}{d x_{2}}<1 \Leftrightarrow v_{x_{1}}^{\prime \prime}+\rho_{11}^{\prime \prime}+\rho_{12}^{\prime \prime}<0$ and for this $\rho_{12}^{\prime \prime}+\rho_{11}^{\prime \prime}<0$ is a sufficient condition. The same reasoning holds for individual 2.

\section{A.2 Proof that there is a unique Nash equilibrium when $\left(x_{1}^{*}>0, x_{2}^{*}>0\right)$}

Proof. A sufficient condition for a unique Nash equilibrium is that the two individuals' best-response curves cross only once.

The slope of 1's best-response function is given in (22) and by assumption $0<\frac{d x_{1}}{d x_{2}}<1$. Equivalently for $2,0<\frac{d x_{2}}{d x_{1}}<1$. Inverting 2's best-response function, gives us $\tilde{x}_{1}\left(x_{2}\right) \equiv x_{2}\left(x_{1}\right)^{-1}$. This function is also upwards sloping, and

$$
\frac{d \tilde{x}_{1}}{d x_{2}}=\frac{u_{2}^{\prime \prime}+\eta\left(v_{2}^{\prime \prime}+\alpha u_{1}^{\prime \prime}+\rho_{22}^{\prime \prime}\right)}{u_{2}^{\prime \prime}+\eta\left(\alpha u_{1}^{\prime \prime}-\rho_{12}^{\prime \prime}\right)}>1 .
$$

Since $\tilde{x_{1}}\left(x_{2}\right)$ is always steeper than $x_{1}\left(x_{2}\right)$ the best-response functions cross only once. Hence, the equilibrium is unique. 


\section{A.3 Proof that a sole donor has higher income than the recipient}

Proof. In equilibrium B, it must be the case that $y_{1}>y_{2}$.

If $u_{1}^{\prime}>u_{2}^{\prime}$, then $u_{1}^{\prime}=\eta\left(v_{x_{1}}^{\prime}+\rho_{1}^{\prime}+\alpha u_{2}^{\prime}\right)$ cannot hold if, at the same time, $u_{2}^{\prime}>\eta\left(v_{0}^{\prime}+\rho_{2}^{\prime}+\alpha u_{1}^{\prime}\right)$ since $v$ is a concave function and $\rho_{1}^{\prime}<0$ and $\rho_{2}^{\prime}>0$. Hence, $u_{1}^{\prime}<u_{2}^{\prime} \Leftrightarrow y_{1}-x_{1}^{*}>y_{2}+x_{1}^{*} \Rightarrow y_{1}>y_{2}$.

\section{B Appendix: Comparative statics concern- ing $x_{1}^{*}$ when $x_{2}^{*}>0$}

In equilibrium $\mathrm{C}$, where $x_{1}^{*}=0$ and $x_{2}^{*}>0$, the first-order condition (4) reads

$$
\left.\Gamma \equiv \frac{\partial U_{1}}{\partial x_{1}}\right|_{x_{2}^{*}>0}=-u_{1}^{\prime}+\eta\left(v_{0}^{\prime}+\alpha u_{2}^{\prime}+\rho_{1}^{\prime}\right)<0 .
$$

Differentiating this gives us the expressions in (15)-(17):

$$
\begin{aligned}
\frac{\partial \Gamma}{\partial y_{1}} & =-u_{1}^{\prime \prime}\left(1+\frac{\partial x_{2}}{\partial y_{1}}\right)+\eta\left(-\alpha u_{2}^{\prime \prime}+\rho_{12}^{\prime \prime}\right) \frac{\partial x_{2}}{\partial y_{1}}, \\
\frac{\partial \Gamma}{\partial y_{2}} & =-u_{1}^{\prime \prime} \frac{\partial x_{2}}{\partial y_{2}}+\eta\left(\alpha u_{2}^{\prime \prime}\left(1-\frac{\partial x_{2}}{\partial y_{2}}\right)+\rho_{12}^{\prime \prime} \frac{\partial x_{2}}{\partial y_{2}}\right), \\
\frac{\partial \Gamma}{\partial \eta} & =-u_{1}^{\prime \prime} \frac{\partial x_{2}}{\partial \eta}+v_{0}^{\prime}+\alpha u_{2}^{\prime}+\rho_{1}^{\prime}+\eta\left(-\alpha u_{2}^{\prime \prime}+\rho_{12}^{\prime \prime}\right) \frac{\partial x_{2}}{\partial \eta} .
\end{aligned}
$$

The responses from individual 2 in terms of altered $x_{2}^{*}$ are equivalent to those derived in equations (11) - (13) and allow us to write 


$$
\begin{aligned}
\frac{\partial \Gamma}{\partial y_{1}} & =\frac{-u_{1}^{\prime \prime}\left(u_{2}^{\prime \prime}\left(1-\eta^{2} \alpha^{2}\right)+\eta\left(v_{x_{2}}^{\prime \prime}+\rho_{22}^{\prime \prime}+\alpha \eta \rho_{12}^{\prime \prime}\right)\right)}{u_{2}^{\prime \prime}+\eta\left(v_{x_{2}}^{\prime \prime}+\alpha u_{1}^{\prime \prime}+\rho_{22}^{\prime \prime}\right)}>0 \\
\frac{\partial \Gamma}{\partial y_{2}} & =\frac{u_{2}^{\prime \prime}\left(-u_{1}^{\prime \prime}\left(1-\eta^{2} \alpha^{2}\right)+\eta\left(\eta \alpha\left(v_{x_{2}}^{\prime \prime}+\rho_{22}^{\prime \prime}\right)+\rho_{12}^{\prime \prime}\right)\right)}{u_{2}^{\prime \prime}+\eta\left(v_{x_{2}}^{\prime \prime}+\alpha u_{1}^{\prime \prime}+\rho_{22}^{\prime \prime}\right)} \gtrless 0 \\
\frac{\partial \Gamma}{\partial \eta} & =\frac{\eta\left(v_{0}^{\prime}+\alpha u_{2}^{\prime}+\rho_{1}^{\prime}\right)\left(u_{2}^{\prime \prime}+\eta\left(v_{x_{2}}^{\prime \prime}+\alpha u_{1}^{\prime \prime}+\rho_{22}^{\prime \prime}\right)\right)+u_{2}^{\prime}\left(u_{1}^{\prime \prime}+\eta \alpha u_{2}^{\prime \prime}-\eta \rho_{12}^{\prime \prime}\right)}{\eta\left(u_{2}^{\prime \prime}+\eta\left(v_{x_{2}}^{\prime \prime}+\alpha u_{1}^{\prime \prime}+\rho_{22}^{\prime \prime}\right)\right)}>0 .
\end{aligned}
$$

In equilibrium (D), where both individuals give positive amounts we totally differentiate the first-order conditions (4) and (5) and obtain the following system:

$$
\begin{gathered}
{\left[\begin{array}{cr}
u_{1}^{\prime \prime}+\eta\left(v_{x_{1}}^{\prime \prime}+\alpha u_{2}^{\prime \prime}+\rho_{11}^{\prime \prime}\right) & -u_{1}^{\prime \prime}-\eta\left(\alpha u_{2}^{\prime \prime}-\rho_{12}^{\prime \prime}\right) \\
-u_{2}^{\prime \prime}-\eta\left(\alpha u_{1}^{\prime \prime}-\rho_{12}^{\prime \prime}\right) & u_{2}^{\prime \prime}+\eta\left(v_{x_{2}}^{\prime \prime}+\alpha u_{1}^{\prime \prime}+\rho_{22}^{\prime \prime}\right)
\end{array}\right] *\left[\begin{array}{c}
d x_{1} \\
d x_{2}
\end{array}\right]} \\
=\left[\begin{array}{ccc}
u_{1}^{\prime \prime} & -\eta \alpha u_{2}^{\prime \prime} & -u_{1}^{\prime} / \eta \\
-\eta \alpha u_{1}^{\prime \prime} & u_{2}^{\prime \prime} & -u_{2}^{\prime} / \eta
\end{array}\right] *\left[\begin{array}{c}
d y_{1} \\
d y_{2} \\
d \eta
\end{array}\right]
\end{gathered}
$$

The system determinant of the LHS matrix in (28) is

$$
\begin{aligned}
|A|= & \eta\left(u_{1}^{\prime \prime}\left[v_{2}^{\prime \prime}+\rho_{22}^{\prime \prime}+\rho_{12}^{\prime \prime}+\alpha \eta\left(v_{1}^{\prime \prime}+\rho_{11}^{\prime \prime}+\rho_{12}^{\prime \prime}\right)\right]\right. \\
& +u_{2}^{\prime \prime}\left[v_{1}^{\prime \prime}+\rho_{11}^{\prime \prime}+\rho_{12}^{\prime \prime}+\alpha \eta\left(v_{2}^{\prime \prime}+\rho_{22}^{\prime \prime}+\rho_{12}^{\prime \prime}\right)\right] \\
& \left.+\eta\left[v_{1}^{\prime \prime} v_{2}^{\prime \prime}+v_{1}^{\prime \prime} \rho_{22}^{\prime \prime}+v_{2}^{\prime \prime} \rho_{11}^{\prime \prime}+\rho_{11}^{\prime \prime} \rho_{22}^{\prime \prime}-\rho_{12}^{\prime \prime 2}\right]\right)>0 .
\end{aligned}
$$


Using Cramer's rule, we get the expressions for the comparative statics when both $x_{1}^{*}>0$ and $x_{2}^{*}>0$. We present the results for $x_{1}$, and those for $x_{2}$ are entirely symmetric:

$$
\begin{aligned}
\frac{\partial x_{1}}{\partial y_{1}} & =\frac{u_{1}^{\prime \prime} u_{2}^{\prime \prime}\left(1-\eta^{2} \alpha^{2}\right)+\eta u_{1}^{\prime \prime}\left(v_{x_{2}}^{\prime \prime}+\rho_{22}^{\prime \prime}+\eta \alpha \rho_{12}^{\prime \prime}\right)}{|A|}>0, \\
\frac{\partial x_{1}}{\partial y_{2}} & =\frac{u_{1}^{\prime \prime} u_{2}^{\prime \prime}\left(1-\eta^{2} \alpha^{2}\right)-\eta u_{2}^{\prime \prime}\left(\rho_{12}^{\prime \prime}+\alpha \eta\left(v_{x_{2}}^{\prime \prime}+\rho_{22}^{\prime \prime}\right)\right)}{|A|} \gtrless 0 \\
\frac{\partial x_{1}}{\partial \eta} & =\frac{-\left(u_{1}^{\prime}\left(u_{2}^{\prime \prime}+\eta\left(v_{x_{2}}^{\prime \prime}+\alpha u_{1}^{\prime \prime}+\rho_{22}^{\prime \prime}\right)\right)+u_{2}^{\prime}\left(u_{1}^{\prime \prime}+\eta\left(\alpha u_{2}^{\prime \prime}-\rho_{12}^{\prime \prime}\right)\right)\right)}{\eta|A|}>0 .
\end{aligned}
$$




\section{Appendix: Summary statistics}

Table 10: Characteristics and definitions of the variables used in the analysis $(\mathrm{N}=2,311)$

\begin{tabular}{|c|c|}
\hline & Mean \\
\hline Social norms1 & $\begin{array}{l}1.22 \\
(.19)\end{array}$ \\
\hline \multicolumn{2}{|c|}{$\begin{array}{l}\text { The community average of the responses to the following two questions: "Most people who } \\
\text { live in this village/neighborhood can be trusted" (yes }=1 / \text { no }=0) \text { and "Most people in this } \\
\text { village/neighborhood are willing to help you if you need it" (yes }=1 / \text { no }=0)^{*}\end{array}$} \\
\hline Social norms2 & $\begin{array}{l}.65 \\
(.22)\end{array}$ \\
\hline \multicolumn{2}{|c|}{$\begin{array}{l}\text { The community average of the responses to the following two questions: "During the last five } \\
\text { years, did you participate with money or work in projects carried out in your community? } \\
\text { (e.g., building a church)" (yes=1/no=0) and "During the last two years, have you offered } \\
\text { active support (not counting when you were paid to do so) to people who needed medical } \\
\text { assistance,to elderly, or to poor people, who are not related to you: (a) through an } \\
\text { organization or association (b) through collaboration with the local government"* }\end{array}$} \\
\hline Private pre-transfer income (per year) ${ }^{* *}$ & $\begin{array}{l}66.844 \\
(71.952)\end{array}$ \\
\hline \multicolumn{2}{|l|}{ Other characteristics: } \\
\hline Female ( $=1$ if household head is female ) & $\begin{array}{l}0.51 \\
(0.50)\end{array}$ \\
\hline Age (of the household head) & $\begin{array}{l}52.58 \\
(15.92)\end{array}$ \\
\hline $\begin{array}{l}\text { Health (dummy }=1 \text { if household head answered very good or good to } \\
\text { "All in all, how would you describe your state of health these days?" }\end{array}$ & $\begin{array}{l}0.54 \\
(0.49)\end{array}$ \\
\hline Household size (number of household members) & $\begin{array}{l}2.06 \\
(1.49)\end{array}$ \\
\hline Children under 18 (in the household) & $\begin{array}{l}0.57 \\
(0.87)\end{array}$ \\
\hline \multicolumn{2}{|l|}{ Education (proportion of household heads with): } \\
\hline Secondary school & 0.27 \\
\hline Technical/High school & 0.39 \\
\hline Post high school & 0.12 \\
\hline University & 0.10 \\
\hline \multicolumn{2}{|l|}{ Regions (dummies for the following eight areas) } \\
\hline South (reference category) & 0.15 \\
\hline Northeast & 0.14 \\
\hline Southeast & 0.16 \\
\hline West & 0.04 \\
\hline Southwest & 0.15 \\
\hline Northwest & 0.17 \\
\hline Center & 0.14 \\
\hline Bucharest & 0.05 \\
\hline $\ln (\mathrm{pop})$ in the community $\ln$ (number of inhabitants) & $\begin{array}{l}10.29 \\
(1.88)\end{array}$ \\
\hline Average consumption in community** & $\begin{array}{l}62.182 \\
(20.46)\end{array}$ \\
\hline
\end{tabular}

Notes: ${ }^{*}$ Social norm values range from 0 to 2 ;

** Monetary values are in 1,000,000 lei (ROL). 1 USD = 32,795 lei (World Bank, 2003).

Standard deviations in parentheses. 